\title{
Detection of Thelazia callipaeda in Phortica variegata and spread of canine thelaziosis to new areas in Spain
}

\author{
Valentina Marino1, Rosa Gálvez', Vito Colella², Juliana Sarquis', Rocío Checa', Ana Montoya', Juan P. Barrera', \\ Sonia Domínguez ${ }^{1}$ Riccardo Paolo Lia², Domenico Otranto ${ }^{2}$ and Guadalupe Miró ${ }^{*}$
}

\begin{abstract}
Background: The fruit fly Phortica variegata (Drosophilidae: Steganinae) feeds on the ocular secretions of animals and humans, and has been described as an intermediate host of the eye worm Thelazia callipaeda (Spirurida: Thelaziidae) in Italy. Despite the increased detection of $T$. callipaeda in many European countries, information about its vector role in natural conditions is still limited. In the Iberian Peninsula, thelaziosis caused by T. callipaeda has been reported in dogs, cats, red foxes, wild rabbits and humans.

Methods: In the last seven years, we have detected increased numbers of cases of canine thelaziosis at three locations in mainland Spain: Site 1, La Vera region (Cáceres Province, central-western Spain; 51 cases); Site 2, El Escorial municipality (Madrid Community, central Spain; 23 cases); and Site 3, Miraflores de la Sierra municipality (Madrid Community, central Spain; 41 cases). Site 1 is considered endemic for T. callipaeda while the other two sites have been recently recognised as risk zones for $T$. callipaeda infection.

Results: From June 2016 to September 2017, 2162 flies were collected and morphologically identified as Phortica spp. (Site 1, $n=395$; Site 2, n= 1544; and Site 3,n=223). Upon dissection, third-stage T. callipaeda larvae were found in two out of 155 flies examined from Site 1, and both these larvae tested molecularly positive for the eye worm. Of the 395 flies collected from Site 1, 371 were molecularly processed for arthropod species identification and T. callipaeda detection. All 371 flies were identified as P. variegata and 28 (7.5\%; 95\% Cl: 4.8-10\%) tested positive for T. callipaeda DNA haplotype 1.

Conclusions: Our findings indicate that T. callipaeda circulates among dogs and P. variegata in Spain, where zoonotic cases have been also reported. The co-existence of canine thelaziosis and Phortica spp. in geographical areas previously considered free of the eye worm indicates a risk of infection for both animals and humans living in this region.
\end{abstract}

Keywords: Phortica variegata, Flies, Vector, Thelazia callipaeda, Eyeworms, Autochthonous cases, PCR, Spain

\section{Background}

Thelazia callipaeda, Railliet \& Henry, 1910 (Spirurida: Thelaziidae) is a nematode that causes eye infection in several mammals, including humans. In their definitive hosts, adult parasites are responsible for subclinical to clinical ocular thelaziosis [1]. The clinical picture produced is mostly the outcome of mechanical damage to the

\footnotetext{
* Correspondence: gmiro@ucm.es

${ }^{1}$ Department of Animal Health, Faculty of Veterinary Medicine, Complutense University of Madrid, Madrid, Spain

Full list of author information is available at the end of the article
}

conjunctival and corneal epithelium caused by the eye worm's serrated cuticle, and of the burden of adult nematodes inhabiting the conjunctival sac [1]. The most common clinical signs are conjunctivitis followed by lachrymal discharge, epiphora and in severe cases, keratitis, corneal opacity or ulcers [1].

Thelazia callipaeda infection has been described not only in dogs and cats but also in red foxes (Vulpes vulpes), gray wolves (Canis lupus), beech martens (Martes foina), brown hares (Lepus europaeus) and wild cats (Felis silvestris) [2]. In the Iberian Peninsula, 
thelaziosis caused by $T$. callipaeda has been detected in red foxes [3, 4] and wild rabbits [5].

Based on initial reports and the high number of cases of $T$. callipaeda in Asia [6,7], the parasite is known as "the oriental eye worm". In Asian countries, human thelaziosis is considered a neglected zoonotic disease due to the high number of cases reported amongst people living in poor and rural areas [8]. In Europe, cases of human thelaziosis have been described in Italy and France [9], Spain [10-12], and more recently, in Croatia and Serbia [13, 14].

In Spain, the first autochthonous case of ocular thelaziosis was reported in 2010 in a dog that had spent a few weeks in the region of La Vera (Cáceres Province, western Spain) [15]. Following further reported cases of canine thelaziosis in this region [16], the geographical area is now considered endemic for canine thelaziosis. Prevalences recorded in dogs of La Vera and bordering areas (provinces of Salamanca, Ávila and Toledo) have been estimated at around $40 \%$ [17, 18]. Of note, in 2012 the first case of feline thelaziosis was detected in La Vera [19].

The distributional range of this nematode infection is thought to be related to that of its vector and intermediate host, Phortica variegata Fallén, 1823 (Drosophilidae: Steganinae) [20-22]. This non-biting fruit fly usually feeds on fermenting fruits and other vegetables, though males display zoophilic behaviour [21]. Phortica variegata and Phortica okadai Okada, 1956 have been described as vectors of $T$. callipaeda in Europe and China, respectively [20, 22]. Under experimental conditions, both males and females can act as vectors of $T$. callipaeda [20], but in natural conditions, only males have been observed to transmit infective third-stage larvae (L3) to the definitive host [21]. To date, reports exist of $P$. variegata acting as intermediate host and vector of $T$. callipaeda under natural conditions only in Italy, although the fruit fly has also been detected in other European countries where autochthonous infections of T. callipaeda have been reported [17, 23].

However, while $P$. variegata is the main vector candidate for $T$. callipaeda in European countries, others species like Phortica semivirgo Máca, 1977 are thought to play a role in the transmission of this eye worm [24]. Furthermore, owing to the similar taxonomic characters of adult worms of $P$. variegata and $P$. semivirgo, identification based only on morphology is difficult and requires specific technical skills (reviewed in [25]).

In this paper, we describe the detection of $P$. variegata specimens naturally infected with $T$. callipaeda in Spain. In addition, we report 115 new cases of canine thelaziosis in three locations of Spain, and assess the seasonal distribution of Phortica spp. in these areas.

\section{Methods}

\section{Sampling sites}

Flies were collected in three different areas of the Iberian Peninsula where cases of thelaziosis in dogs and cats have been reported. The collection sites were designated as:

Site 1. La Vera region (northern Cáceres Province); central-western Spain $\left(40^{\circ} 9^{\prime} 41^{\prime \prime} \mathrm{N}, 5^{\circ} 23^{\prime} 13^{\prime \prime W}\right)$; altitude $472 \mathrm{~m}$ above sea level (masl);

Site 2. El Escorial municipality (northwest Madrid Community); Sierra de Guadarrama $\left(40^{\circ}\right.$ $\left.36^{\prime} 10^{\prime \prime} \mathrm{N}, 4^{\circ} 7^{\prime} 22^{\prime \prime} \mathrm{W}\right)$; altitude 946 masl;

Site 3. Miraflores de la Sierra municipality (northwest Madrid Community); Sierra de Guadarrama $\left(40^{\circ} 48^{\prime} 54^{\prime \prime} \mathrm{N}, 3^{\circ} 46^{\prime} 15^{\prime \prime} \mathrm{W}\right)$; altitude 1147 masl.

At the three study sites, climate and vegetation are typically Mediterranean. Thus, summers are hot and dry, and maximum rainfall is recorded in autumn and spring. The vegetation in these mountainous regions consists of pines (Pinus brutia) and holm oaks (Quercus ilex) in lower areas, and pasture and shrublands in high mountain areas. La Vera region borders with land given over to fruit production (apples, pears, figs, blueberries, raspberries and vineyards). At the three sites, mammals such as deer (Cervus elaphus), wild boar (Sus scrofa), roe deer (Capreolus capreolus), fallow deer (Dama dama), badgers (Meles meles), mustelids, wild cats (Felis silvestris), red foxes (Vulpes vulpes), gray wolves (Canis lupus) and hares (Lepus europaeus) abound [26, 27].

\section{Climate data collection}

Temperatures $\left({ }^{\circ} \mathrm{C}\right)$ and relative humidity, $\mathrm{RH}(\%)$, were recorded using a thermohygrometer (PCE-MHT 1, PCE Instruments, Southampton, UK). Each sampling site was also assigned macroclimate variables (maximum, minimum and average daily temperature, average temperature and precipitation of the current month, and wind speed) provided by the Spanish Meteorological Agency (AEMet) for the closest meteorological station [28].

\section{Diagnosis of thelaziosis in dogs}

All surveyed dogs were subjected to ocular examination after the administration of anaesthetic eye drops (tetracaine hydrochloride and naphazoline hydrochloride). Thelazia callipaeda eye worms were collected from the conjunctival sac of infected dogs using sterile cotton swabs or by flushing with physiological saline solution. In total, 287 dogs were examined at the three sites. At Site 1 , where a prevalence of $40 \%$ had been previously reported for this thelaziosis [17], a population of 75 hunting dogs living outdoors was selected and classified as consisting of "high-risk owned dogs". At Sites 2 and 3 , where veterinarians had reported cases of thelaziosis 
both in dogs and cats (Guadalupe Miró, unpublished observations), 88 and 124 owned dogs were actively sampled, respectively. Animals sampled at Sites 2 and 3 were pets classified as "low-risk owned dogs".

\section{Fly collection, processing and morphological identification}

Non-biting flies were netted with a butterfly net around the eyes of dogs and humans (Fig. 1a). Although trapping is a valid technique, it is not specific and large numbers of other drosophilids may be captured. While time-consuming, netting is a cheap and ready-to-use method.

Flies were captured over a period of about $1 \mathrm{~h}$, usually in the morning. Captured flies were stored in a $20 \times 20 \times 20 \mathrm{~cm}$ cage made from a $0.4 \mathrm{~mm}^{2}$ poresize mesh (Fig. 1b) and transferred to our laboratory at the Department of Animal Health (Faculty of Veterinary Medicine, Complutense University of Madrid) for identification (Fig. 2). The density of flies was calculated as the number of specimens captured over the recorded sampling time.

To detect the presence of L3 T. callipaeda larvae in the flies' proboscis, collected specimens of Phortica spp. were examined by dissection and visual inspection. Only live flies were dissected in a drop of physiological saline. Dead specimens were stored individually in $70 \%$ ethanol. Morphologically identified Phortica spp. flies from Site 1 were also subjected to molecular analyses. All flies (dissected or not) were sexed according to the morphology of the terminal part of the abdomen and stored in $70 \%$ ethanol in individual vials for further analyses.

Morphological identification was performed under a stereomicroscope (Stemi DV4, Carl Zeiss, Göttingen,
Germany) on the basis of taxonomic characters, such as a pale ring around the eyes, yellow tibiae with three dark bands and gray spots on the thorax (Fig. 2) [25, 29]. The unequivocal identification of the species $P$. variegata and $P$. semivirgo is challenging and relies upon the appearance of the terminalia of males and females [25, 29]. The features looked for are the number of sensilla on each medial and dorsal branch of the anterior parameres of the genitalia (3 on each branch for $P$. variegata, 3-5 for P. semivirgo) and the pale ring around the eyes (brownish around the lower half of the eye for $P$. variegata, pale yellow along the whole eye margin for $P$. semivirgo). Some authors have also described intermediate forms in terms of morphological characters for these two species [23]. The proboscis was dissected to retrieve infective $T$. callipaeda larvae, and the abdomen, in particular the terminalia of males, to retrieve different larval stages of T. callipaeda. The number and location of larvae in the body of flies were recorded and the larvae were also identified using morphological keys [20, 30]. Collected T. callipaeda larvae were measured and photographed.

\section{DNA extraction, PCR and sequencing}

Genomic DNA was extracted from individual flies $(n=371)$ and from nematodes $(n=2)$ isolated from two flies, using a commercial kit (DNeasy Blood \& Tissue Kit, Qiagen, Hilden, Germany). A partial sequence of the mitochondrial cytochrome $c$ oxidase subunit 1 gene (coxl, $\sim 689 \mathrm{bp}$ ) was amplified by PCR for the detection of $T$. callipaeda DNA as described in a previous study [31]. To confirm the identification of the flies as $P$. variegata, specimens collected from Site $1(n=371 / 395)$ were subjected to PCR and sequencing, as described elsewhere [32]. In brief, amplicons were purified using Ultrafree-DA columns

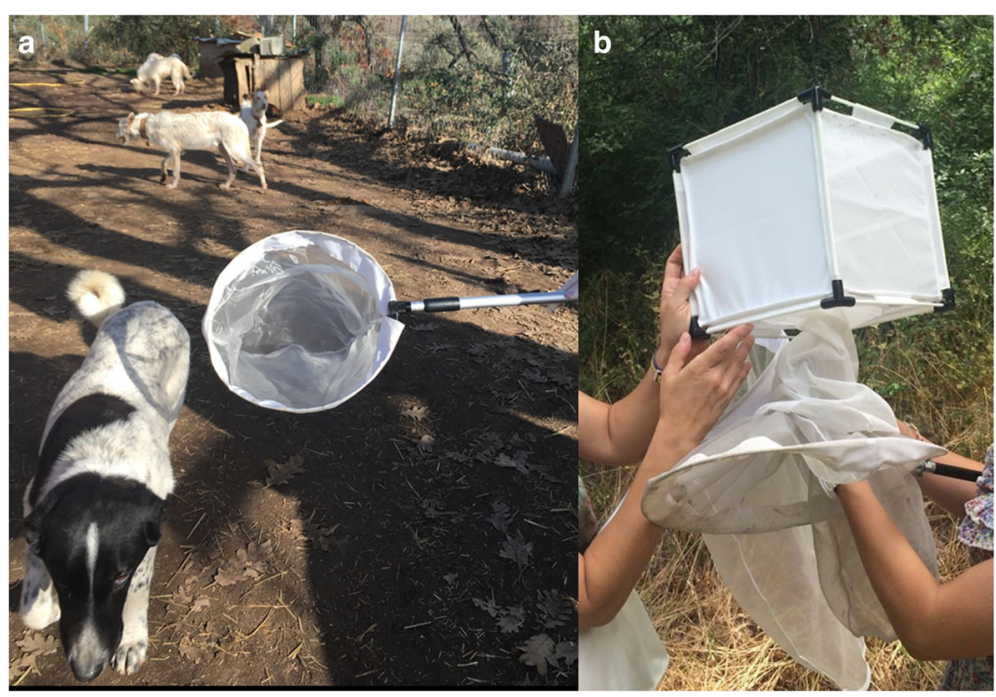

Fig. 1 a Netting procedure. b Cage $(20 \times 20 \times 20 \mathrm{~cm})$ used to store the Phortica flies 


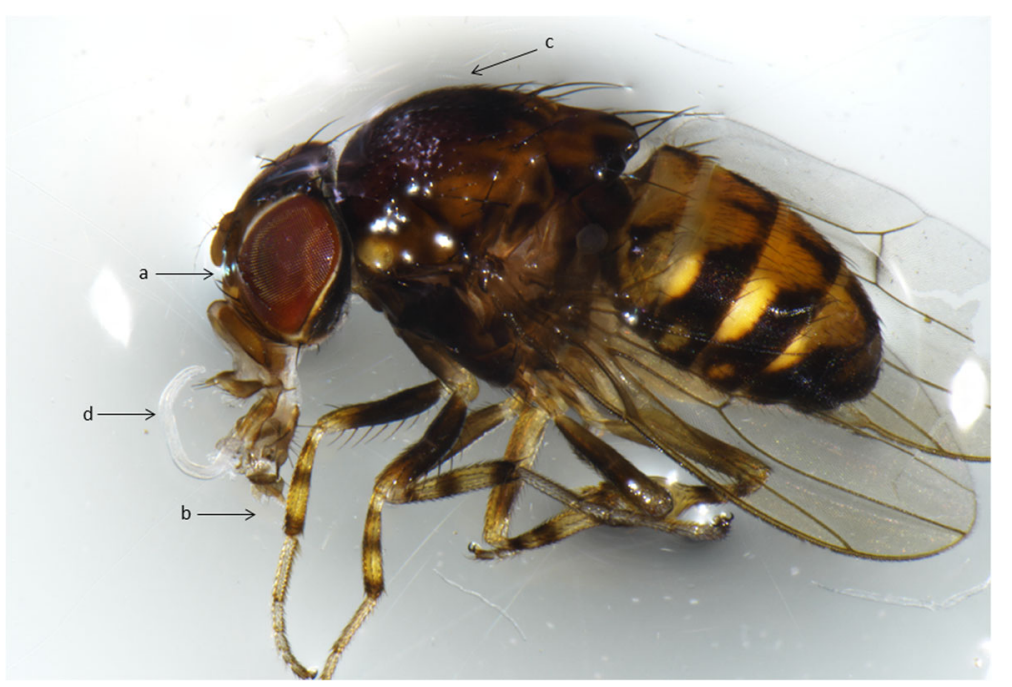

Fig. 2 Male P. variegata, lateral view, showing: a pale ring around the eyes; b yellow tibiae with three dark bands; c grey spots on the thorax and d third-stage $T$. callipaeda larva in the proboscis

(Amicon, Millipore, Bedford, MA, USA) and sequenced directly with the Taq DyeDeoxyTerminator Cycle Sequencing Kit (v.2, Applied Biosystems, Foster, California, USA) in an automated sequencer (ABI-PRISM 377, Applied Biosystems). Sequences were aligned using the Geneious R9 software package [33] and compared (BLASTn) with those available in GenBank [34].

\section{Statistical analysis}

Fly densities were recorded as the number of flies collected in one hour. A descriptive analysis of the main numerical variables recorded (temperature, relative humidity, rainfall, wind speed, density of flies and percentage of males) was performed using mean and standard deviation (SD) or medians and quartile ranges for quantitative variables. Fly density and male percentage were assigned as the dependent variables. Interaction between these two dependent variables and the climate data (independent quantitative variables) was assessed using Spearman's correlation coefficient. For this analysis we used the SPSS 22 statistics package for Windows. Significance was set at $P \leq 0.05$.

\section{Results}

\section{Dogs}

Of the 287 dogs examined at the three sites, 115 (40.1\%, 95\% CI: $34.6-45.8 \%)$ were found to be infected by T. callipaeda. At Sites 1, 2 and 3, the numbers of infected autochthonous dogs were 51 of 75 (68\%, 95\% CI: $56.8-77.5 \%), 23$ of 88 (26.1\%, 95\% CI: $18.1-36.2 \%)$ and 41 of $124(33.1 \%$, 95\% CI: $25.4-$ $41.7 \%)$, respectively. There were significant differences in prevalence between the groups of dogs from the three sites $\left(\chi^{2}=34.012, d f=2, P<0.05\right)$.
Most infected animals presented ocular signs $(n=69$; $60 \%$ ) whereas no clinical signs were observed in 46 dogs (40\%). The clinical signs most frequently observed were conjunctivitis $(n=59 ; 85.5 \%)$, petechiae and oedema $(n=4 ; 5.8 \%)$, keratitis $(n=3 ; 4.3 \%)$ and epiphora $(n=3 ; 4.3 \%)$.

\section{Fly collection and seasonal survey}

In total, 2162 flies (1722 males and 489 females) were collected at the three sites surveyed (Tables 1, 2 and 3). All flies were morphologically identified as belonging to the genus Phortica. Climate data and densities of Phortica spp. captured at Sites 1, 2 and 3 are reported in Tables 1, 2 and 3, respectively.

The numbers of Phortica spp. flies captured at each site over different sampling periods (given in parentheses) were: Site 1 (May-September 2017, $n=395$ ); Site 2 (total $n=1544$; June-November 2016, $n=1410$; AprilSeptember 2017, $n=134$ ); and Site 3 (total $n=223$; September 2016, $n$ = 144; June-September 2017, $n=79$ ).

Overall, Phortica spp. specimens were found in periurban areas characterised by a maximum daily temperature of $35.7^{\circ} \mathrm{C}$ (Site 1 ) and a minimum daily temperature of $2.8^{\circ} \mathrm{C}$ (Site 3). The lowest average daily temperature recorded was $11.8{ }^{\circ} \mathrm{C}$ in April 2017 for Site 2; in these conditions an average of 5.3 flies/h could be collected. No flies were collected when the average daily temperature was $8.8{ }^{\circ} \mathrm{C}$ (November 2016). The highest numbers of Phortica spp. were recorded in August at Site 2, when the average monthly temperature was higher $\left(26^{\circ} \mathrm{C}\right.$ in 2016 and $24.5{ }^{\circ} \mathrm{C}$ in 2017) (Fig. 3). In all places, the total percentage of male Phortica flies (79.65\%) was significantly higher than females (20.35\%). 
Table 1 Density of Phortica spp. captured $(n=395)$ in 2017 at Site 1 (La Vera) and climate variables

\begin{tabular}{|c|c|c|c|c|c|c|c|c|c|}
\hline \multirow[t]{2}{*}{ Month } & \multicolumn{2}{|c|}{ Microclimate variables } & \multicolumn{5}{|c|}{ Macroclimate variables } & \multicolumn{2}{|c|}{ Fly density (flies captured per h } \\
\hline & $\mathrm{T}_{\text {set }}$ & $\mathrm{RH}_{\text {set }}$ & $\mathrm{T}_{\max }$ daily & $T_{\min }$ daily & $T_{\text {mean }}$ daily & $\mathrm{T}_{\text {mean }}$ monthly & Rainfall monthly $(\mathrm{mm})$ & Males & Females \\
\hline May 2017 & 32.9 & 24.3 & 32.0 & 17.0 & 24.5 & 19.8 & 16.4 & 11 & 0.5 \\
\hline June 2017 & 33.8 & 28.8 & 35.7 & 21.0 & 28.4 & 25.7 & 12.8 & 33 & 0 \\
\hline July 2017 & 33.6 & 24.1 & 35.0 & 18.0 & 26.5 & 26.6 & 38.0 & 113.3 & 3.3 \\
\hline August 2017 & 26.7 & 43 & 27.9 & 13.6 & 20.8 & 27.2 & 48.0 & 92 & 3 \\
\hline September 2017 & 32.8 & 29.8 & 31.4 & 17.0 & 24.2 & 23.1 & 0 & 84 & 8 \\
\hline
\end{tabular}

Abbreviations: $T$ temperature $\left({ }^{\circ} \mathrm{C}\right), R H$ relative humidity (\%), $T_{\text {set }}$ Temperature recorded at the time of capture, $R H_{\text {set }}$ relative humidity recorded at the time of capture, $T_{\text {max }}$ maximum temperature, $T_{\min }$ minimum temperature, $T_{\text {mean }}$ mean temperature

At Site 1, numbers of captured Phortica spp. peaked in July, August and September; 96\% of specimens being male $(n=380 / 395)$. At Site $2,74.4 \%(n=1049 / 1410)$ of Phortica spp. captured in 2016 were males, and females were increasingly collected in September and October of this year. In 2017, the proportion of male flies captured at this site was $93.3 \%(n=125 / 134)$ (Fig. 3). At Site 3 , the percentage of male flies collected in September 2016 was 63.2\% $(n=92 / 144)$. The percentage of male flies collected from June to September the following year (2017) was $96.2 \%(n=76 / 79)$.

\section{Bivariate analysis}

Positive moderate correlation was observed between the percentage of male fly specimens collected and the temperature recorded at the time of capture $\left(r_{(17)}=0.53\right.$, $P=0.02$ ). Fly density was also positively correlated with minimum and mean daily temperature, respectively $\left(r_{(24)}=0.45, P=0.02\right.$ and $\left.r_{(24)}=0.42, P=0.04\right)$, and with the mean temperature of the current month, although this time without significance $\left(r_{(24)}=0.50, P=\right.$ $0.11)$. Fly density and the percentage of male flies showed negative correlation $\left(r_{(23)}=-0.44, P=0.03\right)$. No correlations emerged between neither of the dependent variables (fly density and percentage males) and $\mathrm{RH}$ at the time of capture, maximum daily temperature, average monthly rainfall and wind speed (Table 4).

\section{Detection of Thelazia callipaeda in Phortica variegata}

The numbers of flies that were still alive at the time of dissection were 155 (39.2\%), 1088 (70.5\%) and 202 (90.6\%) for Sites 1, 2 and 3, respectively. Upon dissection, one T. callipaeda L3 was detected in each proboscis of two flies collected at Site 1 (Fig. 2), while no flies from Sites 2 and 3 were found to be infected by $T$. callipaeda.

Twenty eight of 371 Phortica flies from Site 1 that were molecularly processed (7.5\%; 95\% CI: $4.8-10 \%)$

Table 2 Density of Phortica spp. captured $(n=1544)$ at Site 2 (El Escorial) and climate variables

\begin{tabular}{|c|c|c|c|c|c|c|c|c|c|}
\hline \multirow[t]{2}{*}{ Month } & \multicolumn{2}{|c|}{ Microclimate variables } & \multicolumn{5}{|c|}{ Macroclimate variables } & \multicolumn{2}{|c|}{ Fly density (flies captured per $h$ ) } \\
\hline & $\mathrm{T}_{\text {set }}$ & $\mathrm{RH}_{\text {set }}$ & $T_{\max }$ daily & $T_{\min }$ daily & $\mathrm{T}_{\text {mean }}$ daily & $\mathrm{T}_{\text {mean }}$ monthly & Rainfall monthly (mm) & Males & Females \\
\hline June 2016 & - & - & 30.9 & 13.6 & 22.3 & 21.3 & 40.0 & 44.0 & 0.4 \\
\hline June $2016^{a}$ & - & - & 35.1 & 19.6 & 27.3 & 21.3 & 40.0 & 86.0 & 3.5 \\
\hline July 2016 & - & - & 29.3 & 10.7 & 20 & 24.0 & 34.8 & 91.5 & 0 \\
\hline August 2016 & 28.4 & 31.7 & 33.7 & 18.4 & 26.1 & 26.0 & 3.6 & 137.2 & 2.0 \\
\hline September 2016 & 25.2 & 24.4 & 27.7 & 14.1 & 20.9 & 21.2 & 14.8 & 56.5 & 60.5 \\
\hline October 2016 & 26.2 & 26.9 & 25.0 & 10.6 & 17.8 & 16.1 & 276.0 & 43.2 & 74.4 \\
\hline October $2016^{\mathrm{a}}$ & 22.0 & 29.8 & 23.5 & 8.9 & 16.2 & 16.1 & 276.0 & 13.3 & 27.3 \\
\hline November 2016 & - & - & 13.8 & 3.7 & 8.8 & 8.6 & 186.8 & 0 & 0 \\
\hline April 2017 & - & - & 18.8 & 4.8 & 11.8 & 14.3 & 32.4 & 5.3 & 0 \\
\hline May 2017 & 29.0 & 32.4 & 30.8 & 17.2 & 24.0 & 17.9 & 29.4 & 10.4 & 0 \\
\hline June 2017 & 26.3 & 32.1 & 26.9 & 15.8 & 21.3 & 24.2 & 31.2 & 33.3 & 0 \\
\hline July 2017 & 26.2 & 25.2 & 30.3 & 15.1 & 22.7 & 24.6 & 188.6 & 16.0 & 0 \\
\hline August 2017 & 28.2 & 35.3 & 32.2 & 17.5 & 24.9 & 24.5 & 49.4 & 112.0 & 2.0 \\
\hline September 2017 & 24.0 & 23.4 & 24.9 & 16.6 & 20.8 & 20.3 & 0 & 38.0 & 16.0 \\
\hline
\end{tabular}

${ }^{a}$ More than one sampling in the same month

Abbreviations: $T$ temperature $\left({ }^{\circ} \mathrm{C}\right), R H$ relative humidity (\%), $T_{\text {set }}$ temperature recorded at the time of capture, $R H_{\text {set }}$ relative humidity recorded at the time of capture, $T_{\text {max }}$ maximum temperature, $T_{\min }$ minimum temperature, $T_{\text {mean }}$ mean temperature 
Table 3 Density of Phortica spp. captured $(n=223)$ at Site 3 (Miraflores de la Sierra) and climate variables

\begin{tabular}{|c|c|c|c|c|c|c|c|c|c|}
\hline \multirow[t]{2}{*}{ Month } & \multicolumn{2}{|c|}{ Microclimate variables } & \multicolumn{5}{|c|}{ Macroclimate variables } & \multicolumn{2}{|c|}{ Fly density (flies captured per h } \\
\hline & $\mathrm{T}_{\text {set }}$ & $\mathrm{RH}_{\text {set }}$ & $\mathrm{T}_{\max }$ daily & $T_{\min }$ daily & $T_{\text {mean }}$ daily & $\mathrm{T}_{\text {mean }}$ monthly & Rainfall monthly $(\mathrm{mm})$ & Males & Females \\
\hline September 2016 & 23.3 & 24.4 & 25.4 & 3.9 & 14.6 & 16.4 & 16.4 & 46 & 26 \\
\hline June 2017 & 30.0 & 24.5 & 28.5 & 5.2 & 16.8 & 19.2 & 59.6 & 10 & 0 \\
\hline July 2017 & 26.3 & 36.9 & 30.8 & 9.0 & 19.9 & 19.5 & 85.6 & 66 & 1 \\
\hline August 2017 & - & - & 31.2 & 9.0 & 20.1 & 19.5 & 132.4 & 6 & 0 \\
\hline September 2017 & - & - & 24.7 & 2.8 & 13.8 & 15.0 & 9.6 & 4 & 4 \\
\hline
\end{tabular}

Abbreviations: $T$ temperature $\left({ }^{\circ} \mathrm{C}\right), R H$ relative humidity (\%), $T_{\text {set }}$ temperature recorded at the time of capture, $R H_{\text {set }}$ relative humidity recorded at the time of capture, $T_{\text {max }}$ maximum temperature, $T_{\min }$ minimum temperature, $T_{\text {mean }}$ mean temperature

returned a positive result for $T$. callipaeda with sequences $100 \%$ identical to those of T. callipaeda haplotype 1 (GenBank: AM042549) and to those obtained for the L3 larvae detected ( $n=2$; Fig. 2, Table 5). Insect nucleotide sequences of flies scoring positive for T. callipaeda DNA $(n=28)$ were $99-100 \%$ identical to those of P. variegata (GenBank: EF576934).

Of the 28 infected flies, one was captured in May ( $n=1 / 9 ; 11.11 \%), 2$ in June $(n=2 / 33 ; 6.06 \%), 11$ in July $(n=11 / 166 ; 6.63 \%)$ and 14 in August $(n=14 /$ 95; 14.74\%; Table 5).

\section{Discussion}

In this study, the detection of T. callipaeda in P. variegata and its potential vectorial role have been described for the first time in Spain. In addition, we report 115 new cases of canine thelaziosis at three localities in Spain, and assess the seasonal distribution of Phortica spp. in these areas, thus confirming that this nematode circulates among dogs and flies. The percentage of infected dogs showing clinical signs (i.e. 60\%) was considerably higher than that recorded in previous studies (15.4\%) [17].
This finding is probably related to the fact that dogs were examined during late stages of infection.

The high prevalence of $T$. callipaeda infection in the dogs from Site 1 (La Vera) was as expected, though still higher (51 out of $75,68 \%$ ) than in an earlier report (i.e. $182 / 456,40 \%$ ) [17]. In contrast, the infection prevalences recorded at the other two sites in Madrid, seven years after the detection of the first infection focus (La Vera), were unexpected, as the affected dogs had not travelled to endemic areas. Indeed, these cases represent new areas of expansion of the parasite within a few years. Differences in prevalence between the groups of dogs from the three sites studied were statistically significant and it may be due to the fact that the infection has been established in Sites 2 and 3 only in the last few years. In addition, dogs from the Site 1 were living outdoors and were selected and classified as consisting of "high-risk owned dogs". Although different animal species (such as red foxes, gray wolves, etc.) have been reported in the three sites, red foxes positive to Thelazia spp. have already been recorded only in Site 1 [3]; this may be associated with the higher prevalence of infection at this site.

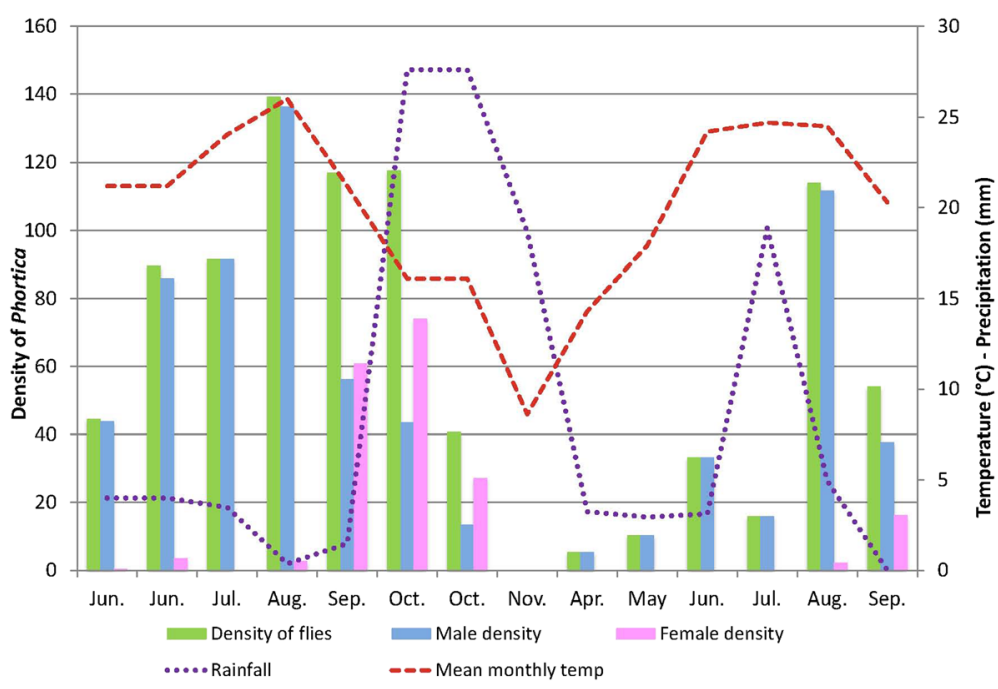

Fig. 3 Seasonal trends in Phortica variegata fly densities (Site 2) 


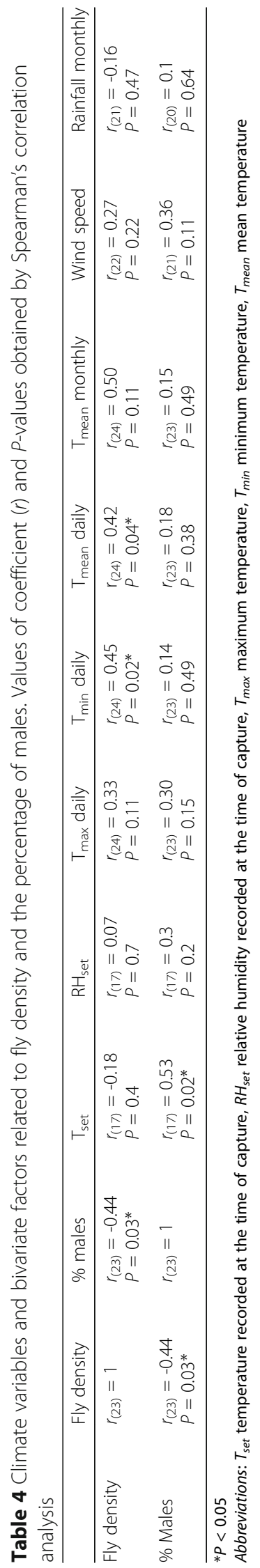


Table 5 Number, sex and positive Phortica spp. from Site 1 dissected between May and September 2017

\begin{tabular}{|c|c|c|c|c|c|c|}
\hline \multirow[t]{3}{*}{ Month } & \multirow{2}{*}{\multicolumn{2}{|c|}{ No. of flies }} & \multirow{2}{*}{\multicolumn{2}{|c|}{$\begin{array}{l}\text { Dissection } \\
\text { Examined (infected) flies }\end{array}$}} & \multirow{2}{*}{\multicolumn{2}{|c|}{$\begin{array}{l}\text { Molecular analysis } \\
\text { Examined (infected) flies }\end{array}$}} \\
\hline & & & & & & \\
\hline & $M$ & $\mathrm{~F}$ & $\bar{M}$ & $\mathrm{~F}$ & $\bar{M}$ & $\mathrm{~F}$ \\
\hline May & 22 & 1 & $14(0)$ & $1(0)$ & $9(1)$ & $0(0)$ \\
\hline June & 33 & 0 & $13(1)$ & $0(0)$ & $33(2)$ & $0(0)$ \\
\hline July & 170 & 5 & $25(0)$ & $5(0)$ & $165(11)$ & $1(0)$ \\
\hline August & 92 & 3 & $50(1)$ & $3(0)$ & $92(14)$ & $3(0)$ \\
\hline September & 63 & 6 & $42(0)$ & $2(0)$ & $62(0)$ & $6(0)$ \\
\hline Total & 380 & 15 & $144(2)$ & $11(0)$ & 361 (28) & $10(0)$ \\
\hline
\end{tabular}

Abbreviations: $F$ female, $M$ male

Furthermore, the co-occurrence of canine thelaziosis and Phortica spp. in areas previously considered free of the parasite determines a risk of infection for animals and humans living in this region, and suggests the likely spread of T. callipaeda among dogs in Spain. To the best of our knowledge, reports so far of canine thelaziosis in the Madrid Community only amounted to imported cases from the La Vera region. These new findings indicate a need to now consider these areas of central Spain as autochthonous for canine thelaziosis.

The first report of $T$. callipaeda in P. variegata was published in 1963 by Kozlov who described larvae in the proboscis of these fruit flies [21]. In 2002 and 2005, $P$. okadaki and $P$. variegata were described as vectors of $T$. callipaeda in China and southern Europe, respectively $[20,22]$. In $2006, P$. variegata was cited as an intermediate host of T. callipaeda [21].

An increase in the occurrence of T. callipaeda in western and eastern Europe has been recently described [35]. In Spain, new cases of thelaziosis are steadily rising in different parts of the country [36], though up until now, the occurrence of $T$. callipaeda in $P$. variegata was reported only in Italy [21].

Our collection sites of Phortica spp. are at the same latitude as other European countries and China where thelaziosis is endemic in the range $39-46^{\circ}$ North, where the dominant vegetation has also been previously associated with the presence of Phortica flies [23, 37-45].

The sex ratio of the Phortica flies was male-oriented, overall proportions of male flies $(1722 / 2162,79.6 \%)$ being significantly higher than female flies $r_{(23)}=-0.44$, $P=0.03$ ). This predominance of males found around the eyes may be explained by dietary habits (these insects supplement their protein intake for gonadotrophic development; reviewed by Otranto et al. [21]). According to a previous survey [23], by netting around the eyes of dogs, $79.6 \%$ of all 2162 Phortica collected were males, and there were only a few females, most of them captured at the end of the summer. Contrary to the results obtained by other authors [21], not all of the present flies collected around the eyes were male. Phortica flies feed on ocular secretions mainly in the second half of the season (July-October), which may be because of dietary needs or because of the higher abundance and activity of Phortica males in these months [21]. As the total number of flies increases at the end of summer, so does the overall number of females. Notwithstanding the previous studies, there is still a lack of knowledge about the behaviour of these flies especially regarding their feeding requirements. This information may be crucial for the design of preventative measures such as repellent formulations targeted at avoiding the feeding of Phortica vectors on infected/uninfected animals.

The length of the activity period of Phortica spp. is largely conditioned by climate conditions. Flies were detected from April when average daily temperatures were $11.8{ }^{\circ} \mathrm{C}$ and the average monthly temperature was $14.3{ }^{\circ} \mathrm{C}$. The number of flies increased with rising temperatures, peaking in August. Finally, at Site 2 the last specimens were captured in September, in line with previous reports [21, 23]. Peaks of $P$. variegata were recorded in mid-summer (August), with temperature being positively correlated with fly density.

By correlating Phortica spp. fly densities with $T$. callipaeda prevalences in dogs, vector densities may be then used to assess the presence of canine thelaziosis in a given area. The prevalence of naturally infected P. variegata reported here (i.e. up to $14.7 \%$ in August; 14 out of 95 flies captured) is higher than that recorded by Kozlov in $1963(1.36 \%)$ [21] and more recently (2006) by Otranto (1.34\%) [21]. We consider that such a high percentage of infected flies could represent a threat, leading to the spread of this parasitosis in Spain. Further studies are needed to confirm this idea and address its consequences.

The molecular approach described in this paper is reliable for detecting species of Thelazia in their different vectors avoiding frequent constraints (e.g. timeconsuming procedures, operator expertise, sensitivity of the methodology, misidentification). We used this approach to investigate the role of flies as vectors along 
with fly dissection and morphological identification of larval stages. In effect, the detection of parasite DNA in arthropod hosts alone is not sufficient proof of their vectorial role or the part played in the ecology of a given vector borne disease. This is because it is not possible to differentiate and even describe larval states in the case of positive results. The molecular characterization of the nematodes examined in the present study served to confirm the identical nature of all cox 1 sequences to those of $T$. callipaeda haplotype 1 . This haplotype has been detected in humans and in domestic animals in Europe [20].

In our study, only $P$. variegata males were found to be infected by $T$. callipaeda, thus confirming the hypothesis that only males act as intermediate host under natural conditions [21]. Unlike other drosophilid species, $P$. variegata feeds on the lachrymal secretions of humans and carnivores [25]. The detection of T. callipaeda exclusively in male specimens of its arthropod vector is of interest from both parasitological and ecological standpoints, and represents a unique case in which a male drosophilid fly feeding on vertebrate host secretions can transmit a vector-borne pathogen under natural conditions [46].

\section{Conclusions}

We here confirm the occurrence of $P$. variegata in Spain and its potential vectorial role of $T$. callipaeda, posing a threat to animals and humans. The results of this study serve to fill gaps in the knowledge of the biological cycle of $T$. callipaeda in southern Europe and offer new prospects for epidemiological studies on thelaziosis and for the design of appropriate control measures. In addition, autochthonous cases of canine thelaziosis are reported for the first time for new areas in Spain.

\section{Abbreviations}

AEMet: Spanish Meteorological Agency; L3: Third-stage larvae; masl: Meters above sea level; SD: Standard deviation

\section{Acknowledgements}

The authors thank the owners of the dogs and the participating veterinarians for their collaboration. We especially thank Carmen Mascuñán from the "Clínica Veterinaria La Cruz Verde", Inés Domínquez and Clara Zenker from "Clínica Veterinaria La Plaza" for their valuable help with the enrolment and follow-up of clinical cases. Publication of this paper was sponsored by Bayer Animal Health in the framework of the 13th CVBD World Forum Symposium.

\section{Funding}

Not applicable.

\section{Availability of data and materials}

All data generated or analysed during this study are included in this published article.

\section{Authors' contributions}

VM performed the field study, processed the samples, carried out the microscopy procedures and drafted the manuscript. RG participated in the diagnostic assays, carried out the statistical analysis of data and reviewed the manuscript. JS, RC and AM participated in the field survey and the diagnostic assays, helping with clinical case enrolment. SD and JB helped with the laboratory work, data collection and with entomological identification. RL contributed to designing the field study and reviewing the manuscript. VC and DO performed the molecular analysis of samples and critically reviewed the manuscript. GM conceived and coordinated the study, participated in its design and the field study, and reviewed the final manuscript. All authors read and approved the final manuscript.

\section{Ethics approval and consent to participate}

The study was carried out in accordance with Animal Protection Spanish Legislation guidelines (Ley 5/2002, Comunidad Autónoma de Extremadura and Ley 4/2016 Comunidad Autónoma de Madrid) and the International Guiding Principles for Biomedical Research Involving Animals, issued by the Council for the International Organizations of Medical Sciences. The worms were extracted by the veterinary practitioners with the agreement and in the presence of dogs' owners.

\section{Consent for publication}

Not applicable.

\section{Competing interests}

The authors declare that they have no competing interests.

\section{Publisher's Note}

Springer Nature remains neutral with regard to jurisdictional claims in published maps and institutional affiliations.

\section{Author details}

${ }^{1}$ Department of Animal Health, Faculty of Veterinary Medicine, Complutense University of Madrid, Madrid, Spain. 'Department of Veterinary Medicine, University of Bari, Valenzano, Bari, Italy.

Received: 6 February 2018 Accepted: 6 March 2018

Published online: 20 March 2018

\section{References}

1. Otranto D, Dantas-Torres F, Brianti E, Traversa D, Petrić D, Genchi C, Capelli G. Vector-borne helminths of dogs and humans in Europe. Parasit Vectors. 2013;6:16.

2. Otranto D, Dantas-Torres F, Mallia E, Di Geronimo PM, Brianti E, Testini G, et al. Thelazia callipaeda (Spirurida, Thelaziidae) in wild animals: report of new host species and ecological implications. Vet Parasitol. 2009;166:262-7.

3. Calero-Bernal R, Otranto D, Pérez-Martín JE, Serrano FJ, Reina D. First report of Thelazia callipaeda in wildlife from Spain. J Wildl Dis. 2013;49:458-60.

4. Sargo R, Loureiro F, Catarino AL, Valente J, Silva F, Cardoso L, et al. First report of Thelazia callipaeda in red foxes (Vulpes vulpes) from Portugal. J Zoo Wildl Med. 2014;45:458-60

5. Gama A, Pires I, Canado M, Coutinho T, Lopes AP, Latrofa MS, et al. First report of Thelazia callipaeda infection in wild European rabbits (Oryctolagus cuniculus) in Portugal. Parasit Vectors. 2016;9:236.

6. Bhaibulaya M, Prasertsilpa S, Vajrasthira S. Thelazia callipaeda Railliet \& Henry, 1910, in man and dog in Thailand. Am J Trop Med Hyg. 1970;19:476-9.

7. Shi YE, Han JJ, Yang WY, Wei DX. Thelazia callipaeda (Nematoda: Spirurida): transmission by flies from dogs to children in Hubei, China. Trans R Soc Trop Med Hyg. 1988;82:627.

8. Shen J, Gasser RB, Chu D, Wang Z, Yuan X, Cantacessi C, et al. Human thelaziosis - a neglected parasitic disease of the eye. J Parasitol. 2006;92:872-6.

9. Otranto D, Dutto M. Human thelaziasis, Europe. Emerg Infect Dis. 2008;14: 647-9.

10. Fuentes I, Montes I, Saugar JM, Latrofa S, Gárate T, Otranto D. Thelaziosis in humans, a zoonotic infection, Spain, 2011. Emerg Infect Dis. 2012;18:2073-5.

11. Gómez-Couso HA-ME, Gómez-Rial MA, Cid-Lama A. Human thelaziosis in Galicia (northwest Spain): report of a clinical case. SOCEPA Congress, Gran Canaria, Spain; 2013, 
12. López Medrano R, Guerra Calleja G, Díez Morrondo C, Panadero Fontán R. Ocular thelaziosis, an emergent zoonosis in Spain. Med Clin (Barc.). 2015; 145:317-8.

13. Paradžik MT, Samardžić K, Živičnjak T, Martinković F, Janjetović Ž, MiletićMedved M. Thelazia callipaeda first human case of thelaziosis in Croatia. Wien Klin Wochenschr. 2016:128:221-3.

14. Tasić-Otašević S, Gabrielli S, Trenkić-Božinović M, Petrović A, Gajić B, Colella $V$, et al. Eyeworm infections in dogs and in a human patient in Serbia: a One Health approach is needed. Comp Immunol Microbiol Infect Dis. 2016; 45:20-2.

15. Guisado A, Sanz F. Conjuntivitis en un perro por Thelazia callipaeda. 6th Andalusian Congress of Veterinarians, 5 November 2010, Benalmadena, Malaga, Spain; 2010

16. VM MA, Hernández L, Dado D, Otranto D, Miro G. Thelaziosis ocular canina ¿Una parasitosis emergente en España? Consulta Difus Vet. 2011;178:43-8.

17. Miró G, Montoya A, Hernández L, Dado D, Vázquez M, Benito M, et al. Thelazia callipaeda: infection in dogs: a new parasite for Spain. Parasit Vectors. 2011:4:148

18. Bello A, Hernández L, Checa R, Dado D, Montoya A, Benito M, et al. Situación epidemiológica actual de la thelaziosis ocular canina en España. XXIX AMVAC Congress, 8-11 March 2012, Madrid, Spain; 2012.

19. Hernández L, Montoya A, Checa R, Dado D, Bello A, Vazquez MV, et al. Primera denuncia de la infección por Thelazia callipaeda en gatos en España. Madrid: XXIX AMVAC Congress, 8-11 March 2012, Madrid, Spain; 2012.

20. Otranto D, Lia RP, Cantacessi C, Testini G, Troccoli A, Shen JL, et al. Nematode biology and larval development of Thelazia callipaeda (Spirurida, Thelaziidae) in the drosophilid intermediate host in Europe and China. Parasitology. 2005;131:847.

21. Otranto D, Cantacessi C, Testini G, Lia RP. Phortica variegata as an intermediate host of Thelazia callipaeda under natural conditions: evidence for pathogen transmission by a male arthropod vector. Int J Parasitol. 2006; 36:1167-73.

22. Wang ZX, Wamg KC, Chen Q. Experimental studies on the susceptibility of Thelazia callipaeda to Amiota okadai in three provinces of China. Chin J Zoonoses. 2002;18:61-3.

23. Roggero C, Schaffner F, Bächli G, Mathis A, Schnyder M. Survey of Phortica drosophilid flies within and outside of a recently identified transmission area of the eye worm Thelazia callipaeda in Switzerland. Vet Parasitol. 2010;171:58-67.

24. Cantacessi C, Traversa D, Testini G, Lia RP, Cafarchia C, Máca J, et al. Molecular identification of Phortica variegata and Phortica semivirgo (Drosophilidae, Steganinae) by PCR-RFLP of the mitochondrial cytochrome oxidase c subunit I gene. Parasitol Res. 2008;103:727-30.

25. Bächli G, Vilela CR, Andersson Escher SAS. The Drosophilidae (Diptera) of Fennoscandia and Denmark, vol. 39. Leiden: Brill; 2004.

26. Rivas-Martínez S, Loidi Arregui JJ. Biogeography of the Iberian Peninsula. Itinera Geobotanica. 1999;13:49-67.

27. Rivas-Martínez S, Rivas-Saez S, Peñas A. Worldwide bioclimatic classification system. Gobal Geobotany. 2011;1:1634.

28. Base de datos Meteorológica. https://datosclima.es/Aemet2013/ DescargaDatos.html. Accessed 30 Oct 2017.

29. Otranto D, Brianti E, Cantacessi C, Lia RP, MáCa J. The zoophilic fruitfly Phortica variegata: morphology, ecology and biological niche. Med Vet Entomol. 2006;20:358-64.

30. Skrjabin KI, Sobolev AA, Ivashkin VM. Principles of Nematology, vol. IX. Spirurata of animals and man and the disease caused by them. Part. 4: Thelazioidea. In: Moscow: Izdatel'stvo Akademii Nauk SSSR; 1967. Jerusalem: English translation Published by Israel Program for Scientific Translations; 1971.

31. Otranto D, Stevens JR, Testini G, Cantacessi C, Máca J. Molecular characterization and phylogenesis of Steganinae (Diptera, Drosophilidae) inferred by the mitochondrial cytochrome c oxidase subunit 1. Med Vet Entomol. 2008;22:37-47.

32. Otranto D, Testini G, De Luca F, Hu M, Shamsi S, Gasser RB. Analysis of genetic variability within Thelazia callipaeda (Nematoda: Thelazioidea) from Europe and Asia by sequencing and mutation scanning of the mitochondrial cytochrome c oxidase subunit 1 gene. Mol Cell Probes. 2005:19:306-13.

33. Molecular Biology and NGS Analysis Tools. http://www.geneious.com. Accessed 5 Sep 2017.
34. The Basic Local Alignment Search Tool. http://blast.ncbi.nlm.nih.gov/Blast.cgi. Accessed 5 Sep 2017.

35. Colella V, Kirkova Z, Fok É, Mihalca AD, Tasić-Otašević S, Hodžić A, et al. Increase in eyeworm infections in eastern Europe. Emerg Infect Dis. 2016:22:1513-5.

36. Marino V, Montoya A, Checa R, Galvez R, Miró G. Situación de la thelaziosis en España: ¿qué ha pasado en los últimos 5 años? AVEPA Congress, 20-22 October, Granada, Spain; 2016.

37. Otranto D, Ferroglio E, Lia RP, Traversa D, Rossi L. Current status and epidemiological observation of Thelazia callipaeda (Spirurida, Thelaziidae) in dogs, cats and foxes in Italy: a "coincidence" or a parasitic disease of the Old Continent? Vet Parasitol. 2003;116:315-25.

38. Dorchies P, Chaudieu G, Siméon LA, Cazalot G, Cantacessi C, Otranto D. First reports of autochthonous eyeworm infection by Thelazia callipaeda (Spirurida, Thelaziidae) in dogs and cat from France. Vet Parasitol. 2007;149:294-7.

39. Malacrida F, Hegglin D, Bacciarini L, Otranto D, Nägeli F, Nägeli C, et al. Emergence of canine ocular thelaziosis caused by Thelazia callipaeda in southern Switzerland. Vet Parasitol. 2008;157:321-7.

40. Vieira L, Rodrigues FT, Costa Á, Diz-Lopes D, Machado J, Coutinho T, et al. First report of canine ocular thelaziosis by Thelazia callipaeda in Portugal. Parasit Vectors. 2012;5:124

41. Soares C, Sousa SR, Anastácio S, Matias MG, Marquês I, Mascarenhas S, et al. Feline thelaziosis caused by Thelazia callipaeda in Portugal. Vet Parasitol. 2013;196:528-31.

42. Hodžić A, Latrofa M, Annoscia G, Alić A, Beck R, Lia R, et al. The spread of zoonotic Thelazia callipaeda in the Balkan area. Parasit Vectors. 2014;7:352.

43. Motta B, Nägeli F, Nägeli C, Solari-Basano F, Schiessl B, Deplazes P, et al. Epidemiology of the eye worm Thelazia callipaeda in cats from southern Switzerland. Vet Parasitol. 2014;203:287-93.

44. Mihalca A, D’Amico G, Scurtu I, Chirilă R, Matei I, lonică A. Further spreading of canine oriental eyeworm in Europe: first report of Thelazia callipaeda in Romania. Parasit Vectors. 2015:8:48

45. Diakou A, Di Cesare A, Tzimoulia S, Tzimoulias I, Traversa D. Thelazia callipaeda (Spirurida: Thelaziidae): first report in Greece and a case of canine infection. Parasitol Res. 2015;114:2771-5.

46. Otranto D, Stevens JR, Cantacessi C, Gasser RB. Parasite transmission by insects: a female affair? Trends Parasitol. 2008;24:116-20.

\section{Submit your next manuscript to BioMed Central and we will help you at every step:}

- We accept pre-submission inquiries

- Our selector tool helps you to find the most relevant journal

- We provide round the clock customer support

- Convenient online submission

- Thorough peer review

- Inclusion in PubMed and all major indexing services

- Maximum visibility for your research

Submit your manuscript at www.biomedcentral.com/submit 